\title{
O PENSAMENTO ARQUEOLÓXICO E ANTROPOLÓXICO DE LEANDRO SARALEGUI Y MEDINA (1839-1910)
}

\author{
Por \\ FERNANDO PEREIRA GONZÁLEZ
}

Cando tratamos coa historia da arqueoloxía galega durante o século XIX, axiña salientan, a partir da segunda metade desa centuria, os nomes de tres personaxes fundamentais no desenvolvemento da arqueoloxía na Galicia decimonónica: José Villaamil y Castro, Manuel Martínez Murguía e Leandro Saralegui y Medina.

Pódese dicir - aínda a risco de esquecer outras figuras importantes como Ramón Barros Sivelo, Eladio Oviedo Arce, Marcelo Macías e a Comisión Provincial de Monumentos de Ourense, a Sociedad Arqueológica de Pontevedra ou os primeiros pasos de Federico Maciñeira-que estes tres homes xogaron un papel fundamental na práctica e na popularización da arqueoloxía no noso país durante o século pasado, aínda que en cada caso particular isto foi debido a motivos un tanto diferentes.

Sobre José Villaamil y Castro non hai ningunha dúbida de que el foi o personaxe máis senlleiro da arqueoloxía galega durante a segunda metade do século XIX; foi el quen levou a cabo as primeiras escavacións realizadas en Galicia cun carácter minimamente científico (ó longo das décadas de 1860 e 1870), seguindo os métodos e as ideas vixentes na arqueoloxía prehistórica noutros países europeos. Foi tamén el o primeiro en aplicar a Galicia o concepto de Prehistoria, e o primeiro en tentar definí-las etapas da prehistoria galega. Ademais foi un dos principais

"CUADERNOS DE ESTUDIOS GALLEGOS", Tomo XLIII, Fascículo 108, Santiago 1996. 
promotores do malogrado Museo Arqueológico Central de Galicia, fundado en Santiago de Compostela en 1884 a iniciativa da Sociedad Económica de Amigos del País desa cidade.

Se Villaamil salienta pola súa práctica arqueolóxica, Murguía, pola súa banda, faino pola súa contribución teórica, pois foi el quen retomou e reformulou unha idea que marcaría toda reflexión histórica e toda práctica arqueolóxica en Galicia ata a actualidade: o «Celtismo». Efectivamente, recollendo a idea dun pasado celta para Galicia, presente en autores galegos da primeira metade do XIX como Verea y Aguiar e Martínez Padín (que á súa vez a tomaran de autores franceses que reivindicaban un pasado galo/celta para o seu país), ou en contemporáneos seus, como Benito Vicetto, Murguía fixo do «Celtismo» galego, inserido gracias a el dentro das novas correntes da ciencia europea, un argumento para apoialo feito diferencial galego, argumento que se cónvertiu en adiante nunha especie de dogma para rexionalistas e nacionalistas, e nunha idea que condicionou fortemente o estudio e a imaxe da protohistoria galega.

«Celtista» (e rexionalista) como Murguía, o propio Saralegui tiña, sen embargo, uns intereses arqueolóxicos máis amplos qué Murguía, a quen en materia de arqueoloxía só lle interesaba o pasado céltico de Galicia, e quen, polo demais, chegaba a desprecia-las épocas prehistóricas anteriores ós «seus» celtas. Precisamente a Saralegui debemos algunhas das reflexións máis interesantes que se fixeron na Galicia da época, pola novidade que daquela supuxeron, verbo da prehistoria galega e da prehistoria da humanidade en xeral. O seu coñecemento do que se pensaba e do que se estaba a facer por entón na Europa Occidental no eido da arqueoloxía prehistórica (e a súa parcial adhesión ás teorías presentadas por ela), a súa creación dunha imaxe concreta do pasado prehistórico de Galicia, e o seu desexo de divulgar e de popularizar no noso país as investigacións arqueóloxicas, son quizais, os riscos máis salientables da contribución de Saralegui á arqueoloxía galega, da cal, ata agora, pouco se ten dito ${ }^{1}$. O seu pensamento acerca destas cuestións amosa características

\footnotetext{
1 Sobre o labor e o pensamento arqueolóxicos de José Villaamil y Castro, o fundamental está recollido en Llana Rodríguez (1990 e 1994) e Pereira González (1995 e 1996a). Os estudios sobre Murguía son, paradoxalmente, moi escasos, tanto na súa vertente histórica, como en relación á arqueoloxía ; para o emprego da información arqueolóxica por parte de Murguía, véxase Pereira González (1995). Sobre o pensamento arqueolóxico de Leandro Saralegui y Medina véxase Pereira González (1995 e 1996a).
}

"CUADERNOS DE ESTUDIOS GALLEGOS", Tomo XLIII, Fascículo 108, Santiago 1996. 
propias do seu século, presentes en toda Europa, e tamén outras máis peculiares do caso galego, como é a síntese de arqueoloxía prehistórica, «Celtismo» e as tradicións historiográficas sobre o pasado galego.

De seguida verémolo máis polo miúdo.

\section{ALGÚNS APUNTAMENTOS BIOGRÁFICOS}

Leandro Saralegui y Medina naceu en Tui en 1839 e morreu e Ferrol en 1910. Militar, integrado na Mariña, en 1854 pasou a formar parte do Corpo Administrativo da Armada, e ó longo da súa carreira ocupou altos cargos na administración militar: director da Academia de Administración da Mariña en Ferrol, interventor do Departamento Naval de Cádiz e do Apostadero de Filipinas, Intendente da Mariña en Ferrol, Intendente Xeneral do Ministerio de Mariña...

Combinou a súa carreira militar cun amplo labor de erudito en grande medida autodidacta, abranguendo obras sobre temática naval e militar, estudios sobre literatura galega, investigacións sobre a historia de Ferrol, ensaios sobre economía e política, e, o que máis nos interesa aquí, diversos traballos acerca do pasado prehistórico de $\mathrm{Galicia}^{2}$, en especial do seu «pasado celta». Ademais desenvolveu un intenso labor xornalístico, colaborando en numerosas revistas da época, e sendo director entre 1909 e 1910 do Almanaque Ferrolano, revista onde publicou varios artigos de temática histórica e arqueolóxica.

Todos estes intereses plasmáronse na súa pertenza a varias sociedades eruditas; foi membro da Real Academia Gallega, da Real Academia de la Historia, da Sociedad Económica de Amigos del País de Madrid, Cartagena e Filipinas, e da Sociedad Arqueológica de Pontevedra.

Entre as súas obras, libros e artigos, cómpre citar: Estudios sobre la época céltica en Galicia (que coñeceu tres edicións, en 1867, 1888 e 1894, respectivamente), Tratado de Economía Política (primeira edición de 1870, logo coñeceu varias edicións nas décadas seguintes), Galicia y sus poetas (1886), Estudios sobre Galicia (1888), «La cuestión obrera en

\footnotetext{
${ }^{2} \mathrm{O}$ seu irmán, Manuel Saralegui y Medina, tamén integrado na Armada, interesouse igualmente pola arqueoloxía, publicando en 1918 Los monumentos megalíticos de España.
}

"CUADERNOS DE ESTUdIOS GALLEGOS", Tomo XLIII, Fascículo 108, Santiago 1996. 
Galicia» (1893), «San Martín de Jubia. Apuntes históricos» (1893), «Del Monte Ancos» (1898), «La futura historia de Ferrol» (1901), «Ardobrica. Estudio de Geografía Histórica» (1908), «Libunca. Estudio histórico» (1909).

En relación á temática do presente artigo, hai que salienta-la primeira e a terceira edicións de Estudios sobre la época céltica en Galicia e, sobre todo, os seus Estudios sobre Galicia, recopilación de artigos redixidos por Saralegui dende comezos de 1870 (algúns xa publicados anteriormente nalgunhas revistas galegas) sobre temas diversos -economía, política, literatura-, pero no que predominan os traballos de materia arqueolóxica, gracias ós cales coñecemos as opinións de Saralegui sobre a arqueoloxía prehistórica e albiscámo-la evolución do seu pensamento dende 1867, data da primeira edición de Estudios sobre la época céltica en Galicia. Serán estes dous libros os que terei en conta principalmente para coñece-lo seu pensamento arqueolóxico e antropolóxico, aínda que tamén será necesario achegarse ás súas opinións políticas e económicas, plasmadas noutros dos seus traballos, para ver cómo estas actuaban sobre aquel co gallo de comprendelo mellor.

Precisamente, en relación ó seu posicionamento ideolóxico, Leandro Saralegui compartía con Manuel Murguía, outro dos persoeiros da historia e da arqueoloxía galegas do XIX, o ideario do rexionalismo liberal, caracterizado, como ten indicado Ramón Maíz, polo seu desexo de descentralización do estado español e de autogoberno para Galicia, de democratización do estado e de desenvolvemento capitalista. Era este un proxecto político ideado por unha minoría erudita e estaba destinado a unha case inexistente, e moi desartellada, burguesía galega (Máiz, 1984).

Nalgúns dos seus traballos, como en «El Regionalismo en Galicia», publicado, como outros dos seus artigos, en Galicia. Revista Regional, e posteriormente integrado na recopilación Estudios sobre Galicia, ou na súa introducción á terceira edición de Estudios sobre la época céltica en Galicia, Saralegui amosábase un firme partidario do rexionalismo -ideoloxía, segundo el, defensora da diversidade e valedora dos dereitos e dos intereses de Galicia-, á vez que rexeitaba o separatismo e negaba os intereses dos rexionalistas galegos de se uniren con Portugal. Pero Saralegui era, asemade, un afervoado valedor do liberalismo económico e social, do laissez faire, e rexeitaba calquera tipo de intervencionismo estatal, á vez que louvaba sempre o esforzo e a iniciativa individual, que eran para el os verdadeiros motores do Progreso.

"CUADERNOS DE ESTUDIOS GALLEGOS", Tomo XLIII, Fascículo 108, Santiago 1996. 
Sen embargo, e a diferencia de Murguía e doutros historiadores e eruditos galegos da época, Saralegui, segundo se desprende do estudio de Ramón Máiz, non participou na organización do movemento rexionalista galego durante a derradeira década do século XIX e a primeira da presente centuria, malia a súa orientación claramente rexionalista e as súas aportacións teóricas (nomeadamente no eido económico).

Cómo se relacionaba a súa ideoloxía rexionalista e liberal co seu pensamento arqueolóxico e antropolóxico verémolo máis adiante. Agora vou pasar a presenta-las súas ideas sobre a prehistoria da humanidade.

\section{O PASADO PREHISTÓRICO}

As opinións de Saralegui verbo do pasado prehistórico da humanidade atópanse fundamentalmente nos diversos artigos de temática arqueolóxica incluídos en Estudios sobre Galicia (1888): «Los Castros. Estudios de Arqueología Prehistórica», «Labor Omnia Vincit», «Los arios en Galicia», «La Edad de la Piedra en Galicia» e «Pueblos lacustres». Estes artigos foron escritos, segundo consta nese libro, en varias datas - 1885, $1872,1885,1876$ e 1870, respectivamente-, e algúns deles xa foran publicados anteriormente; por exemplo, «Los Castros. Estudios de Arqueología Prehistórica» publicárase en 1887 na revista Galicia, aínda que do resto dos artigos mencionados non teño ningunha noticia da súa publicación anterior a 1888, cando apareceron en Estudios sobre Galicia.

O que se desprende deles acerca da prehistoria da humanidade é o seguinte:

Saralegui cría na grande antigüidade da humanidade, aínda que rexeitaba a teoría de que o ser humano fose o resultado da evolución dalgunha especie de primate; para el, os seres humanos apareceran na Terra había centos de miles de anos (non especificaba cómo), posiblemente xa a finais do periodo Terciario. Deste xeito, se ben a humanidade podía ser considerada moi antiga a respecto das opinións que foran correntes nas décadas anteriores (e que, con todo, aínda se mantiñan), que falaban dunha humanidade non máis antiga de 6.000 anos (ou, como moito, 10.000 anos), pola contra, en relación á historia da Terra e dos outros seres vivos, que contaban con miles de millóns de anos de existencia, os humanos eran moi recentes.

"CUADERNOS DE ESTUdIOS GALLEGOS", Tomo XLIII, Fascículo 108, Santiago 1996. 
Rexeitaba, polo tanto, a cronoloxía tradicional dada á humanidade que estaba baseada na Biblia. E a súa opinión sobre o estado orixinal dos seres humanos tampouco coincidía co consignado no Libro da Xénese. Pois opinaba que nun principio eses primeiros seres humanos vivían case como animais (o que non quería dicir, sen embargo, que Saralegui os considerase animais ou descendentes de animais), sen posuíren os máis mínimos rudimentos de civilización. A súa era unha dura existencia, sempre en guerra contínua contra os elementos, as bestas salvaxes e entre eles mesmos. E, paradoxalmente, este estado de contínua loita foi o que levou ós primeiros humanos a da-los primeiros pasos cara a unha existencia plenamente humana. As guerras e a loita contra os animais impulsounos a emprega-los primeiros útiles, ó principio, unicamente pónlas de árbores, ósos ou toscos instrumentos de pedra; máis tarde, útiles máis perfeccionados. Contra as inclemencias do tempo e os ataques dos animais procuraron refuxio nas covas, e, casualmente, descubriron cómo facer lume. E a vida nas covas e ó redor do lume favoreceu a creación de vencellos sociais entre as persoas e deu lugar á orixe da linguaxe, formándose as primeiras sociedades... O que aconteceu despois xa é coñecido. $\mathrm{O}$ esforzo contínuo destinado a satisface-las máis diversas necesidades levounos dun invento a outro, cada vez máis sofisticados, cada vez dominando máis a natureza: pedra puída, cerámica, agricultura, construcción de cabanas, metalurxia, etc..., e así ata a era industrial.

A intelixencia, xa presente nos seres humanos dende un principio, pero necesitada dun meirande desenvolvemento, aguilloada pola necesidade, fixo posible as primeiras bases da civilización —os útiles e o lume-, concibidas como defensa contra unha natureza hostil. E nun proceso de feedback, esa intelixencia que fixera posible os primeiros inventos, viuse favorecida por eles, desenvolveuse e «creou» novos inventos, que á súa vez actuaron de novo positivamente sobre as capacidades mentais humanas.

Dende o momento no que os primeiros humanos empregaron bastos útiles de pedra - nese momento, segundo Saralegui, «faise» o ser humano- a humanidade enceta o seu longo camiño de Progreso. Falaba Saralegui das Tres Idades prehistóricas: a Idade da Pedra (subdividida á súa vez en Paleolítico e Neolítico), a Idade do Bronce e a do Ferro, e falaba das novidades que trouxeran e das melloras que estas implicaran, bases doutras melloras posteriores...

"CUADERNOS DE ESTUDIOS GALLEGOS", Tomo XLIII, Fascículo 108, Santiago 1996. 
Esta era, claramente, unha visión da historia humana, e da súa prehistoria, en termos de Progreso, un Progreso contínuo froito do esforzo, do traballo e da iniciativa, necesarios para cubri-las necesidades que o medio impuña ós humanos.

E era unha visión que, en esencia, coincidía coa que por esa mesma época mantiñan os antropólogos e os prehistoriadores partidarios do evolucionismo cultural, como Lubbock, Tylor, Mortillet, ou, no estado español, Vilanova y Piera e Sales y Ferré, que falaban dunha humanidade que estivera en contínua evolución cultural dende a Idade da Pedra ata a revolución industrial (e que continuaría evolucionando no futuro), e que se esforzaban en delimita-los estadios sucesivos e as causas desa evolución, moitas veces concibida como unilinear, é dicir, que toda a humanidade debía pasar polos mesmos estadios de «civilización», aínda que só uns poucos grupos humanos (a «raza branca», segundo a ideoloxía etnocentrista e racista da época) foran quen de chegar ó máis alto.

Saralegui sen dúbida compartía bastantes ideas con este evolucionismo cultural - a crenza na grande antigüidade da humanidade, o estado de «salvaxismo» orixinal da mesma, que daba paso paseniño a un proceso de mellora contínuo, producto do esforzo e da inventiva dos propios humanos. Incluso en ocasións demostraba ser partidario do evolucionismo unilinear, falando das semellanzas que presentaban sociedades diferentes e afastadas entre si pero que se atopaban no mesmo estadio cultural. Pero Saralegui nunca chegou a preocuparse por todo o proceso de evolución cultural da humanidade nin polos mecanismos de evolución, centrado como estaba, fundamentalmente, no pasado prehistórico de Galicia. E, ademais, combinaba certas afirmacións do evolucionismo unilinear, é dicir, unha teoría da cultura que implicaba un proceso de progreso cultural basicamente contínuo (o Progreso producíase pola propia evolución interna dunha sociedade determinada), cunha visión invasionista e descontínua do progreso cultural, afirmando que este se producía cando pobos ou «razas» de intelixencia «superior» creaban formas de cultura máis «elevada» (un exemplo eran os indoeuropeos que aportaran a metalurxia e novas ideas relixiosas, etc.) que eran transmitidas despois a sociedades máis «atrasadas» mediante invasión e conquista das mesmas, ou ben por outras canles de difusión. Así, para Saralegui, o Progreso da humanidade era fundamentalmente descontínuo e estaba marcado pola acción daqueles pobos máis «capaces», entre os que Saralegui salientaba os indoeuropeos. Por suposto que estas ideas de 
Saralegui non eran orixinais, senón que por entón eran bastante comúns en Europa (en Galicia eran compartidas, por exemplo por Murguía ou por Octavio Lois).

Xa que logo, a imaxe que tiña Saralegui acerca do pasado prehistórico era moi semellante á aceptada nos círculos arquelóxicos e antropolóxicos máis progresistas do estado español e da Europa Occidental. Pero tamén era «case» totalmente oposta á visión que mantiñan sobre a humanidade primitiva os círculos máis conservadores, nomeadamente os relixiosos e os eruditos máis influídos por estes. Eles non querían escoitar falar da grande antigüidade do ser humano (como moito aceptaban unha antigüidade de 10.000 anos), nin dos primeiros humanos que vivían nun estado de «salvaxismo» case animal, nin, moito menos, da orixe simia da humanidade. Para eles o ser humano era unha creación divina, o cume da creación, a obra máis perfecta de Deus, e cando aquel apareceu na Terra xa posuía o aspecto físico e a intelixencia que o caracterizaba no presente; xa contaba cunha organización social e cunha tecnoloxía - aínda que rudimentarias-, e, gracias a unha Revelación divina inicial, xa desfrutaba de ideas relixiosas e de normas morais que, fixadas por Deus mesmo, eran inmutables e universais. E axiña desfrutou da agricultura e da metalurxia, como constaba no libro da Xénese, libro que dende o punto de vista deses círculos conservadores continuaba a se-lo guieiro a seguir no relativo á primeira historia da humanidade. Crían no Progreso da humanidade, pero o camiño de Progreso seguido pola humanidade non era resultado dos seus propios esforzos, senón que era o desexo dunha divindade que dirixía a marcha da Historia. E moi a míudo Progreso identificábase con Cristianismo.

Esta visión tradicional da humanidade e da Historia era a maioritaria na Galicia do século XIX, non só nos círculos eclesiásticos, senón tamén na Universidade e, polo menos ata a segunda metade do século, noutros círculos de eruditos como os afeccionados á historia do país. A Igrexa galega atacaba a arqueoloxía prehistórica e a antropoloxía evolucionista, disciplinas ás que consideraba materialistas e ateas, falsas ciencias que só anceiaban unha cousa: destruí-la relixión católica e as súas «verdades eternas» ${ }^{3}$.

${ }^{3}$ Sobre as opinións da Igrexa e dos sectores conservadores da Universidade na Galicia decimonónica verbo do evolucionismo biolóxico e da arqueoloxía prehistórica, véxase Mayobre Rodríguez (1985), Fraga Vázquez (1992 e 1993) e Pereira González (1996a).

"CUADERNOS DE ESTUDIOS GALLEGOS", Tomo XLIII, Fascículo 108, Santiago 1996. 
$\mathrm{Na}$ Galicia decimonónica non foron moitos os valedores das novas ideas sobre a humanidade que presentaban antropólogos e prehistoriadores. A grande influencia da Igrexa, o escaso desenvolvemento das investigacións antropolóxicas e arqueolóxicas no país, a prudencia (ou o conservadurismo) dos poucos estudiosos que a estas disciplinas se dedicaron, ou o desinterese que moitos deles sentiron pola cuestión da humanidade primitiva, centrados como estaban no pasado galego e nos celtas... todo isto pesou para que os debates sobre a humanidade primitiva fosen practicamente inexistentes en Galicia durante o século XIX, e para que só unha minoría se decidise a apoia-las ideas da grande antigüidade da humanidade e da súa evolución a partir dos primates, do estado de «salvaxismo» orixinal, e da evolución cultural producto unicamente do esforzo humano (Pereira González, 1996a).

Leandro Saralegui y Medina pertenceu a esa minoría, aínda que el non aceptou a orixe simia da humanidade, e aínda que seguía a crer na actuación da Providencia na Historia humana. Pero malia isto, Saralegui foi unha das persoas que na Galicia da pasada centuria máis se achegou a esa nova concepción do pasado da humanidade.

\section{PREHISTORIA E PROTOHISTORIA DE GALICIA}

Como bo «celtófilo» que era, Saralegui afirmaba sen ningún tipo de dúbida que Galicia era un país eminentemente «celta», como de feito aseguraban unha boa parte dos eruditos galegos do século XIX e primeira metade do XX. E esa orixe celta do pobo galego era o que confería a Galicia a súa esencia, o que configuraba o seu carácter e singularizaba tódalas súas manifestacións culturais. Segundo o discurso «celtista» dominante, compartía Galicia a súa orixe celta con outros países do oeste europeo, como Bretaña, Irlanda, Gales ou Escocia, e as semellanzas culturais que atopaban Saralegui e outros autores entre todos estes países e o noso -ás que se facía referencia en numerosas ocasións- eran para eles unha proba de teren todos unha descendencia común. A carón destas probas de tipo etnográfico, enumeraba tamén Saralegui probas filolóxicas (as supostas palabras celtas que se conservaran na toponímia e no idioma galego), arqueolóxicas (os monumentos megalíticos e os castros) e os textos de autores greco-romanos que falaban de tribos celtas na Gallaecia.

"CUADERNOS DE ESTUDIOS GALLEGOS", Tomo XLIII, Fascículo 108, Santiago 1996. 
Para Saralegui, o pobo galego era o herdeiro directo das tribos celtas que habitaran o territorio da actual Galicia durante a protohistoria e que, finalmente, tras unha longa loita contra o invasor romano, foran vencidas e incorporadas ó imperio forxado por Roma.

Pero a pesar da súa conquista os celtas souberan resistir á asimilación - malia perderen a súa lingua - conservando os seu caracter e os seus costumes, caracter e costumes que pasaran practicamente intactos ó pobo galego actual, e que se atopaban en estado máis puro entre a pobación labrega do interior do país, da cal citaba Saralegui algúns dos seus costumes e crenzas para ilustra-la relixión dos antigos celtas, ¡tan fielmente se conservara a herdanza celta entre os campesiños galegos!.

Os celtas, polo tanto, ocupaban un lugar central na visión que tiña Saralegui do pasado pre-romano galego, e isto quedaba ben demostrado pola monografía que o autor dedicou á «época céltica» do noso país - $\mathrm{o}$ xa citado Estudios sobre la época céltica en Galicia, que coñeceu tres edicións-, e polas numerosas referencias ós celtas que se atopan nos seus artigos de temática arqueolóxica.

Na primeira edición de Estudios sobre la época céltica en Galicia, de 1867, presentaba as probas que demostraban a presencia dos celtas en Galicia, e realizaba un estudio sobre a súa lingua, os seus xeitos de vida, costumes e relixión, e os seus monumentos. Afirmaba que os celtas pertencían á familia indoeuropea, que proviña de Asia e que chegara a Europa no II milenio antes de Cristo. Nesta primeira edición do libro aseguraba que os celtas foran a primeira poboación de Galicia (a historia galega anterior ós romanos non era, pois, moi extensa), e, seguindo ó historiador francés A. Thierry, falaba de dúas vagas de tribos celtas separadas no tempo: primeiro chegaron os Galos e, máis tarde, os Kimris. Dende a súa chegada ó territorio galego os celtas estiveron en contacto con numerosos pobos, dos cales adoptarían algúns avances tecnolóxicos (comercio, industria, navegación...) e novas ideas relixiosas. Así, Saralegui falaba da chegada a Galicia, posteriormente ós celtas, dos Vénetos (pobo procedente da Bretaña), os fenicios, os gregos, os cartaxineses, e, finalmente, os romanos.

A crenza na presencia de fenicios, gregos e cartaxineses en Galicia durante un pasado remoto era xa un lugar común na historiografía galega anterior ó secúlo XIX, e polas datas nas que escribía Saralegui esa sucesión de pobos convertírase nun dogma case tan firme como o dos 
celtas, e estaba presente tamén noutros historiadores galegos decimonónicos. A aparición dos Vénetos nesa sucesión era unha novidade de Saralegui que non tería continuación na historiografía posterior.

Esta era a visión do pasado pre-romano galego que tiña Saralegui na primeira edición de Estudios sobre la época céltica en Galicia. Era unha visión moi semellante á que daquela tiña Manuel Murguía ou, se ben con algunhas diferencias máis, á de Vicetto, Verea y Aguiar e Martínez Padín. $\mathrm{O}$ interese estaba centrado case exclusivamente nos celtas, que se consideraban a primeira (ou polo menos a máis importante) poboación do país antes da chegada dos romanos.

Pero na terceira edición da obra, de 1894, a imaxe do pasado galego era algo diferente. A aceptación por parte de Saralegui de moitas das implicacións da arqueoloxía prehistórica, como demostraba nos seus artigos recollidos en Estudios sobre Galicia, levoulle a facer algunhas modificacións.

En primeiro lugar, a aceptación da grande antigüidade da humanidade e da existencia dunha longa época prehistórica, fixo que xa non puidese afirmar que os celtas foran a primeira poboación de Galicia, datada tan só do II milenio antes da nosa era. Agora éralle forzoso recoñecer que os celtas eran, de feito, un pobo recente no territorio galego, e que moito antes de eles chegaren Galicia xa estaba habitada por outras xentes, por varios pobos que se sucederon uns a outros, e dos que nos daba noticias a arqueoloxía. Deste xeito na terceira edición de Estudios sobre la época céltica en Galicia, e xa anteriormente nalgúns artigos como «Los Castros. Estudios de Arqueología Prehistórica», «Los Arios en Galicia» ou «La Edad de Piedra en Galicia», ofrecíanos Saralegui unha das primeiras divisións da prehistoria galega, do pasado pre-céltico. Fiel á súa postura «invasionista» Saralegui concibía a prehistoria de Galicia como unha sucesión contínua de pobos: novos pobos chegados de lonxe e portadores de novos avances tecnolóxicos, sociais ou ideolóxicos substituían ás xentes que ocuparan anteriormente o territorio.

O seu esquema era o seguinte: obviando os traballos de José Villaaamil y Castro, que apuntaran a posibilidade da existencia dun Paleolítico galego, Saralegui afirmaba que aínda non se atoparan en Galicia restos que indicasen no noso país a existencia dunha primeira Idade da Pedra (o Paleolítico), pero si falaba da presencia dun pobo «neolítico» que, procedente de Asia, introducira en Galicia a agricultura, os útiles de pedra

"CUADERNOS DE ESTUDIOS GALLEGOS", Tomo XLIII, Fascículo 108, Santiago 1996. 
puída e as vivendas lacustres - as palafitas-, presencia demostrada, segundo el, polo achado de numerosos machados de pedra puída; despois deste pobo «neolítico» chegou outro pobo asiático que trouxo os monumentos megalíticos, os cales en 1867 Saralegui aínda consideraba de orixe exclusivamente celta; e, por fin, farían a súa aparición os celtas, pobo indoeuropeo, e, polo tanto, tamén de procedencia asiática. Os celtas, coa súa maior capacidade para a civilización, aportaron o uso dos metais e novas formas de hábitat, os castros, á vez que adoptaron o costume anterior de erixir monumentos megalíticos, os cales, deste xeito, cumpría diferenciar entre os de orixe pre-celta e os que pertencían xa ós celtas. O resto da historia xa é coñecida: chegada dos Vénetos, fenicios, gregos, Kimris (a segunda vaga de pobos celtas, que traían consigo a relixión druídica), cartaxineses e romanos.

Como se pode comprobar, a aceptación dun longo pasado prehistórico xa non permitía a Saralegui basear toda historia anterior ós romanos unicamente nos celtas, aínda que estes seguían a ser para el o máis importante ó se-los configuradores da personalidade propia de Galicia. Pero agora cumpría tamén ter en conta as xentes que poboaran Galicia antes dos celtas, e isto só se podía conseguir gracias á arqueoloxía. Como xa dixen, a de Saralegui foi unha das primeiras subdivisións da prehistoria galega realizada con base na arqueoloxía (anteriormente esbozara outra Villaamil y Castro), e, aínda que era moi breve e esquemática (e está, evidentemente, superada), e a pesar de que non estaba apoiada en escavacións nin nun estudio detallado do material arqueolóxico galego (nin sequera citaba os traballos de Villaamil y Castro), merece que recoñezámo-la súa importancia polo feito de que foi pioneira nunha época na cal o remoto pasado de Galicia era case sempre dominio absoluto dos celtas.

Con todo, a nova disciplina da arqueoloxía prehistórica non era quen de desterrar do pasado galego a hexemonía dos celtas, nin as tradicionais colonizacións fenicia, grega e cartaxinesa. Todo o máis que podía conseguir era engadir un longo periodo prehistórico anterior ós celtas poboado por xentes descoñecidas de procedencia asiática, ó que se engadía a imaxe «ortodoxa» decimonónica do pasado pre-romano galego.

Saralegui, polo tanto, compartía o discurso «celtista» con Murguía, o principal valedor e promotor do mesmo, discurso que moitos autores, e entre eles Saralegui, farán que se convirta na «historia oficial» do pasado 
galego; e serán fundamentalmente autores de ideoloxía galeguista (rexionalistas e despois nacionalistas) os que se encarguen disto. $\mathrm{O}$ peculiar de Saralegui a respecto doutros autores galegos do momento era a súa meirande curiosidade polo pasado pre-celta (que compartía con Villaamil y Castro) e pola humanidade primitiva.

E tanto o seu interese polo pasado celta como algunhas das súas ideas verbo da humanidade primitiva reflecten certos aspectos da súa ideoloxía.

\section{IDEOLOXÍA, ARQUEOLOXÍA E ANTROPOLOXÍA}

¿Cómo influiu a ideoloxía de Saralegui no seu pensamento arqueolóxico e antropolóxico?. Verémolo de contado. Pero antes debo aclarar que neste breve apartado non pretendo realizar un estudio polo miúdo das ideas políticas, económicas ou relixiosas de Leandro Saralegui, nin unha análise pormenorizada da súa influencia noutros ámbitos do pensamento do autor. Todo isto implicaría unha detallada investigación da súa vida e da súa obra, e máis espacio do que aquí se dispón. Con todo, si quero sinala-las relacións máis evidentes que se poden albiscar entre a súa ideoloxía e varias das súas opinións arqueolóxicas e antropolóxicas.

Debo, en primeiro lugar, indicar un vencello evidente entre o seu interese polo pasado de Galicia, ben a súa Prehistoria ou épocas máis recentes, e a súa postura rexionalista. Esta relación entre ideoloxía galeguista (no caso de Saralegui, rexionalista) e interese polo pasado galego é un feito ben constatado polos estudiosos da historiografía galega dos séculos XIX e $\mathrm{XX}^{4}$, e fica ben demostrado nos nomes e na obra de Vicetto, Murguía, Vaamonde Lores, Tettamancy Gastón, Amor Meilán ou os membros doSeminario de Estudos Galegos. O estudio da historia do país convertíase nun xeito de reafirma-la súa propia identidade, á vez que o pasado era empregado como un instrumento para comprender e explicalo presente e tamén, en ocasións, para construí-lo futuro. E moitas veces ese mesmo pasado, considerado como glorioso ou preferible, compensaba en certa maneira dos problemas e das frustacións do presente.

Leandro Saralegui insírese dentro desta corrente que, polo demais, non é privativa de Galicia, xa que nos países e nos momentos máis diversos o

\footnotetext{
${ }^{4}$ Sobre isto véxase Mato Domínguez (1981) e Barreiro Fernández (1988 e 1993)
} 
estudio da historia foi moitas veces da man do patriotismo. Saralegui sábeo, e el mesmo di, despois de estudia-lo pasado celta de Galicia, que esta é unha investigación «eminentemente patriótica», e engade: «Hoy es vergonzoso que no tratemos de consagrar toda nuestra atención al cultivo de la prehistoria gallega, ya que no por amor de la ciencia, al menos por el buen nombre de nuestra patria» (Saralegui y Medina, 1894).

Isto enlaza con outra das características do pensamento arqueolóxico de Saralegui influída tamén pola súa ideoloxía: o seu «Celtismo». É ben sabido que para moitos autores «celtistas» a súa elección do elemento «celta» como a verdadeira esencia do pobo galego produciuse seguindo unha determinada inclinación política: o galeguismo, nas súas variantes de provincialismo, rexionalismo e nacionalismo. O pasado celta de Galicia, que o diferenciaba doutras rexións do estado español de pasado «íbero», segundo a historiografía española da época, actuaba como un garante do feito diferencial galego, dunha personalidade ben diferenciada do país, que estaría presente xa, de acordo coas teorías celtistas, dende os comezos da historia de Galicia 5 .

Se ben a recurrencia a un pasado celta para Galicia non sempre implicou a súa utilización como mito-base do feito diferencial galego - por exemplo no caso de José Verea y Aguiar quen ó identificar galegos con celtas só pretendía defender a Galicia e a toda a parte norte da Península, céltica toda ela, das «aldraxes históricas» que contra elas se cometeran ó longo dos anos (Mato Domínguez,1981)—, 'é certo tamén que xa nos círculos provincialistas, Benito Vicetto por exemplo, e, sobre todo, nos rexionalistas, con Murguía á fronte, o pasado celta actuaba como mito de orixe da «patria galega», dándolle ó país unha personalidade propia que se mantería ó longo dos séculos e que servía de xustificación dos anceios de autogoberno. Este emprego político do «celtismo» está moi claro en Manuel Murguía ou en autores posteriores como Vicente Risco ou Ramón Otero Pedrayo. Por suposto que a ideoloxía rexionalista de Saralegui achegábao máis á postura de Murguía cá de Verea y Aguiar, pois na súa obra o elemento celta aparece sempre marcando a singularidade de Galicia a través de toda a súa historia (consideraba que a dominación celta do país foi «una de las glorias más legítimas de Galicia»

\footnotetext{
${ }^{5}$ Sobre o celtismo na historiografía galega do século XIX e primeira metade do XX véxase Vieites Torreiro (1987).
}

"CUADERNOS DE ESTUDIOS GALLEGOS", Tomo XLIII, Fascículo 108, Santiago 1996. 
e chama ós celtas «la primitiva nacionalidad gallega»), condicionando incluso o seu futuro (que se supón esperanzador); así, no artigo «Los Castros. Estudios de Arqueología Prehistórica», refírese ós celtas como «un pueblo que vive todavía hoy como perpetuado en el espíritu provincial y en los destinos de nuestra raza» (Saralegui y Medina, 1888).

Xa dixen antes que as opinións arqueolóxicas e antropolóxicas de Leandro Saralegui inseríanse na meirande parte das veces nas correntes do pensamento europeo da época; isto era ben visible, como xa apuntei máis arriba, nas súas ideas verbo da humanidade primitiva. E tamén se comproba na súa adhesión ó que León Poliakov ten denominado «o mito ario», é dicir, a construcción ó longo do século XIX dunha determinada imaxe dos pobos indoeuropeos, daquela considerados en moitas ocasións como membros dunha raza, a «raza aria» (Poliakov, 1971). Esta «raza aria», á que pertencían os pobos celtas, era considerada unha raza «superior» (e branca, por suposto) portadora da civilización, unha raza activa e creadora que dirixía os destinos do mundo. E Saralegui, como tamén Murguía ( $c f r$. Máiz, 1984), facíase partícipe deste «mito ario», mito claramente racista e moitas veces anti-semita (como no caso de Murguía). Así pois, en Murguía, en Saralegui ou, posteriormente, en Vicente Risco, a fundamentación histórica da nacionalidade galega apoiábase en presupostos raciais e racistas, feito habitual en diversos nacionalismos europeos de entón, tanto de estados-nación como de nacións sen estado.

No artigo «Los Arios en Galicia» expuña as súas opinións ó respecto: os celtas son indoeuropeos, e os indoeuropeos son unha raza civilizadora (eles introducen en Europa a metalurxia ou novas ideas relixiosas «máis elevadas», como fixeron en Galicia os celtas) e dunha meirande beleza física, pois son de tez branca e dolicocéfalos; e afirmaba que o perfeccionamento moral ía parello do perfeccionamento físico. En fin, como dicía nese mesmo artigo: «La sola posesión del bronce, en que se anticiparon á todos los demás pueblos de la tierra, constituía un título de superioridad tan trascendental como incontestable, que facilitó a los arios la conquista del mundo» (Saralegui y Medina, 1888:139).

De tódolos xeitos cómpre recoñecer que os aspectos racistas e antisemitas do «mito ario» non aparecen tan marcados en Saralegui como si o fan en Manuel Murguía.

Pero o racismo de Saralegui non se limitaba a facerse eco do «mito ario», senón que se manifestaba tamén no seu pensamento «racial», que,

"CUADERNOS DE ESTUDIOS GALLEGOS", Tomo XLIII, Fascículo 108, Santiago 1996. 
por outra banda coincidía co habitual na cultura occidental de entón. En moitas ocasións Saralegui semellaba identificar pobos con razas; así falaba de pobo celta ou de raza celta, de pobo galego e de raza galega. E, como se reflectía nalgunhas das súas afirmacións, unha raza (e polo tanto, un pobo) tiña unhas características físicas determinadas (presentes na forma do cranio, nas faccións do rostro...) e unhas características «espirituais», morais ou intelectuais concretas (que se reflectían no «xeito de ser» desas xentes así como na súa cultura). Así quedaría explicada a singularidade dopobo/raza celta, e, por extensión, a do pobo/raza galego/ a. E esas razas (ou pobos) mantiñan as súas características inmutables ó longo do tempo, sen se perderen ó se mesturaren con outras poboacións (Saralegui conta que cada pobo recén chegado a Galicia elexía un hábitat determinado segundo as súas preferencias «raciais»-os celtas as montañas e as fragas, os fenicios a costa, etc-, o que explicaba a non mestura de poboacións e o mantemento dos tipos «raciais»). Velaí por qué os galegos conservaron tan fielmente a súa herdanza celta; non era só por fidelidade á propia cultura, senón que era algo que «se levaba dentro» quixérase ou non, era cuestión de raza. Sendo de raza celta, os galegos non podían máis que mante-las características físicas e mentais dos seus devanceiros que loitaran valentemente contra os romanos.

E, como era habitual no século XIX, falar de razas implicaba, case inevitablemente, falar de xerarquías raciais, de «razas superiores» e de «razas inferiores».

É certo que nas obras de Saralegui non aparecía unha xerarquía racial deste tipo aplicada a poboacións determinadas (como si aparecía en numerosos tratados de antropoloxía decimonónicos), pero non é menos certo que o seu tratamento dos pobos indoeuropeos situábaos, como el mesmo especificaba, nun nivel superior, considerados unha «raza» civilizadora que rexía os destinos do mundo. E, no polo oposto, estaban situados os pobos de cor, as poboacións indíxenas de América, Africa ou Oceanía, que Saralegui vía estancados no mesmo estadio de cultura cós pobos da Europa prehistórica. Eses pobos de cor eran, polo tanto, atrasados, non tiñan afán polo traballo, eran lacazáns, libertinos, brutos e supersticiosos. Eran, pois, todo o contrario á «raza aria», «raza» activa e amante do Progreso.

Vemos aquí establecida unha xerarquía por Saralegui, aínda que non o facía en termos especificamente raciais. Pero as diferencias raciais eran algo que ficaban implícitas.

"CUADERNOS DE ESTUDIOS GALLEGOS", Tomo XLIII, Fascículo 108, Santiago 1996. 
Unha vez comprobadà a postura racista de Saralegui, é posible comprender mellor a súa visión «invasionista» da historia e o seu difusionismo. Segundo el, só os primeiros inventos culturais -o lume, os útiles de pedra, o acubillo nas cavernas, os vestidos-estiveran ó alcance de toda a humanidade; pero inventos máis complexos —os metais, por exemplo- só foran acadados por aquelas razas máis capaces (sic) e unicamente pasaran a outras poboacións con menor capacidade de invención (sic) a través da difusión ou das invasións (Saralegui, 1894). Xa se viu como Saralegui salientaba estas últimas; de feito, a prehistoria e a protohistoria de Galicia eran para el o escenario de invasións sucesivas, por medio das cales se introducían no país os novos adiantos da civilización. O Progreso acadábase cando os recén chegados máis «civilizados» se superpuñan ás poboacións anteriores máis «atrasadas». «Os máis civilizados (os máis preparados) prevalecen», parece querernos dicir Saralegui. É a supervivencia do «máis apto» a nivel de pobos (ou razas).

Isto tamén gardaba relación, sen dúbida, coa defensa a ultranza que Saralegui facía do liberalismo, sobre todo no eido económico. Na súa obra de 1870 Tratado de Economía Política, ou en artigos como «La cuestión obrera e Galicia» (1893), o autor amosábase totalmente en contra da intervención estatal na economía (ou, como no caso do devandito artigo, do control estatal das condicións de traballo dos obreiros); para el o librecambio, a iniciativa privada, o esforzo, o traballo contínuo eran as únicas garantías de que progresase a economía e a sociedade.

Ecos deste pensamento librecambista pódense atopar igualmente na súa imaxe da humanidade primitiva. Xa se viu máis arriba como para Saralegui o esforzo e o traballo realizados para satisface-las necesidades das persoas eran a verdadeira causa do Progreso da humanidade. Os primeiros humanos vivían nun estado de loita contínua, contra o clima, contra os animais salvaxes, ou entre eles mesmos. A tecnoloxía, as vivendas, a sociedade mesma eran productos desa loita, dos esforzos dos seres humanos para sobrevivir e para levar unha existencia mellor. As necesidades, pois, e o esforzo realizado para satisfacelas eran o motor do Progreso. Un grupo humano que dende o primeiro momento tivese cubertas tódalas súas necesidades - por exemplo nun medio ambiente abundante en alimentos e nun clima benigno - non necesitaría esforzarse e ficaría estancado sen progresar. A iniciativa e o esforzo, bases do liberalismo económico, víanse trasladadas á prehistoria.

"CUADERNOS DE ESTUDIOS GALLEGOS", Tomo XLIII, Fascículo 108, Santiago 1996. 
A este respecto é moi ilustrativo comparar estas dúas citas de Saralegui pola grande semellanza que gardan entre elas. A primeira está tirada do seu Tratado de Economía Política, e a segunda dun artigo de temática arqueolóxica que leva o significativo título de «Labor Omnia Vincit»:

«El hombre no pone en juego sus facultades, no desplega su actividad y no multiplica sus esfuerzos, sinó porque tiene necesidades que satisfacer, porque necesita alimentarse, cultivar su inteligencia, y aplicar á sus semejantes el sentimiento de amor que constituye al ser moral. (...) La multiplicidad de sus necesidades, combinada con la precisión de satisfacerlas, es la base inquebrantable del progreso social. El hombre exento de necesidades ó con muy escasas atenciones, se limitaría á la producción de un número determinado de artículos, sin pensar en extender sucesivamente la acción de las facultades con que le ha dotado la naturaleza» (Saralegui y Medina, 1870: 333-334).

«Si la naturaleza, en el momento de abrir sus ojos á la luz, lo hubiera acogido en su regazo maternal, colmándolo de delicias y de inefables placeres (...) el hombre no habría empezado jamás á abrir los caminos de su futura felicidad y su legítimo engrandecimiento, viviendo como aletargado en medio de los encantos y la dulzuras de una existencia paradisíaca. La especie humana sería hoy la misma de la época terciaria, sin aumento en las necesidades ni progreso en los medios, semejante á las tribus africanas que vejetan como petrificadas en medio de los bosques vírgenes de un continente inexplorado» (Saralegui y Medina, 1888:123).

Igualmente, Saralegui eríxese en defensor da propiedade privada, que para el era outra garantía para que as persoas traballasen e se esforzasen e se movesen na dirección do Progreso. A aqueles pobos que non recoñecesen a propiedade privada só lles agardaba unha vida de apatía e de nugalla, unha vida "de privaciones, de abyección y miseria»; sen propiedade privada «la vida es ni más ni menos la del Salvaje de Nueva Holanda ó de Vanikero» (Saralegui y Medina, 1870: 167).

Queda clara, pois, a mensaxe de Saralegui: esforzo, iniciativa privada e propiedade privada conducen á humanidade polo camiño do Progreso.

"CUADERNOS DE ESTUDIOS GALLEGOS", Tomo XLIII, Fascículo 108, Santiago 1996. 
E Saralegui quere exemplificar isto non só con acontecementos contemporáneos, senón que recúa ata a prehistoria para demostralo, condicionando polo tanto a súa visión da humanidade primitiva.

Saralegui é, xa que logo, un firme crente na idea de Progreso, idea común no mundo occidental ó longo do século $\mathrm{XIX}^{6}$. O Progreso víase como algo inevitable, e descubríase en tódolos aspectos da vida: na aparición dos seres vivos a través da longa historia de Terra; na historia humana, dende a prehistoria ata a era industrial... E se ata entón todo fora progresando inevitablemente, non había razón para pensar que as cousas non continuasen igual no futuro. Todo indicaba $\longrightarrow$ un pasado e un presente de Progreso indicaban - que a xente podía olla-lo futuro con optimismo, e en especial as clases medias, a burguesía á que pertencía Leandro Saralegui, pois este era o grupo social que sen dúbida fora o máis favorecido coa marcha progresiva da humanidade. O presente era deles, e, seguramente, tamén o futuro. Era esta unha visión tranquilizadora do futuro que se vía confirmada no pasado.

A fe no Progreso era unha característica das clases medias decimonónicas, e Saralegui, defensor do liberalismo, da industrialización, e da modernización do país, compártea. Cómpre, con todo, puntualizar que para el o Progreso non estaba unicamente nas mans dos humanos; malia salienta-lo esforzo humano como garante do mesmo, Saralegui seguía a reservar un papel na historia á Providencia, pois era Deus quen, dun xeito ou doutro, facía que un pobo determinado estivese ou non destinado a progresar, ó situalo nun medio ambiente máis ou menos favorable.

Saralegui compartía a idea de que o Progreso estaba (en última instancia) nas mans da Providencia con outros autores galegos da época, liberais coma el, como Murguía e Vicetto, demostrando con isto que a relixiosidade seguía a ser unha nota predominante no pensamento galego decimonónico, e en concreto na visión da historia humana (débese lembrar que nin Saralegui, nin Murguía, nin Vicetto, aceptaban a idea da orixe simia do ser humano; ó contrario, vían o ser humano como o cumio da creación divina).

\footnotetext{
${ }^{6}$ Sobre a idea de Progreso no século XIX e os seus efectos sobre as distintas disciplinas científicas véxase o libro de Peter J. Bowler (1989) The Invention of Progress. The Victorians and the Past.
}

"CUADERNOS DE ESTUdiOs GALLFGoS ', Tomo XLIII, Fascículo 108, Santiago 1996. 
Para rematar gustaríame insistir en que tódalas ideas que vimos ata aquí, configurando a ideoloxía de Saralegui e deixando as súas pegadas nas súas opinións arqueolóxicas e antropolóxicas, podíanse inserir nas correntes de pensamento europeo presentes na segunda metade do século XIX, o que amosa que Saralegui, como Murguía, estaba profundamente influenciado por estas. Neste sentido, pódese considerar a Saralegui como un autor «típico» da súa época.

\section{A MODO DE CONCLUSIÓN: LEANDRO SARALEGUI Y MEDINA NO PANORAMA ARQUEOLÓXICO GALEGO DO SÉCULO XIX}

Para poder situar correctamente a Leandro Saralegui na arqueoloxía galega do século pasado cómpre en primeiro lugar pasar revista, brevemente, ás principais características do panorama arqueolóxico galego durante a segunda metade do século pasado ${ }^{7}$. Estas pódense resumir en:

1. Dende principios do século produciuse un recoñecemento da grande importancia que tiñan as investigacións arquelóxicas para poder coñecelo pasado de Galicia, especialmente o máis remoto, o anterior ós romanos. Este recoñecemento aparecía en toda a historiografía galega decimonónica que se ocupou da Galicia romana e pre-romana.

2. Malia todo este recoñecemento da importancia da arqueoloxía, a práctica arqueolóxica - escavacións, estudio do material arqueolóxico galego- foi bastante escasa. Como exemplos máis sobranceiros da devandita práctica (e case os únicos) hai que cita-los traballos de Ramón Barros Sivelo, José Villaamil y Castro, Eladio Oviedo Arce, Santiago de la Iglesia, as escavacións na Catedral de Santiago na procura dos restos do Apóstolo, e o labor desenvolvido a finais de século pola Comisión Provincial de Monumentos de Ourense e a Sociedad Arqueológica de Pontevedra.

\footnotetext{
7 Acerca disto ve-lo meu traballo de investigación $O$ emprego da información arqueolóxica en Galicia:1800-1922 (Pereira González, 1995). Un resumo do mesmo pódese ver en Pereira González (1996b).
}

"CUADERNOS DE ESTUDIOS GALLEGOS", Tomo XLIII, Fascículo 108, Santiago 1996. 
3. As máis das veces o pasado pre-romano de Galicia era «construído» sen ter en conta a información arqueolóxica, apoiándose fundamentalmente na interpretación que os distintos autores facían dos textos clásicos. Era unha prehistoria (é dicir, aqueles tempos anteriores á conquista romana, como definira Villaamil y Castro a prehistoria galega) sen arqueoloxía.

4. Nos casos nos que a información arqueolóxica se utilizaba para «construir» ese pasado, o seu emprego era bastante superficial; case nunca estaba baseado nun verdadeiro traballo arqueolóxico, con escavacións e estudio do material, senón que se limitaba a inserir distintos elementos arqueolóxicos (mámoas, castros, etc.) en esquemas históricos xa dados de antemán («Celtismo», presencia dós fenicios è Galicia, teorías da arqueoloxía europea...). A información arqueolóxica devén na meirande parte dos autores galegos do momento nunha simple referencia.

5. Dominio case absoluto da teoría «celtista» ó interpreta-lo pasado pre-romano.

6. Falla de apoio e de interese por parte das institucións. O fracaso da iniciativa daSociedad Económica de Amigos del País de Santiago de crear un museo arqueolóxico en Compostela foi un bo exemplo disto. Por outra banda na Universidade galega nunca houbo en todo o século XIX posibilidade de estudiar arqueoloxía. Unicamente no Seminario compostelán existía unha asignatura de Arqueología Sagrada, centrada na arte cristiá. A práctica da arqueoloxía realizouse soamente polo interese e a vontade dunhas poucas persoas.

7. Durante todo este século non existiron en Galicia verdadeiros debates ou discusións verbo da humanidade primitiva (a súa orixe, antigüidade e desenvolvemento), como si aconteceu, nomeadamente a partir da segunda metade da centuria, noutras partes do estado español e na Europa occidental. Sen embargo si se poden atopar no noso país ideas sobre este tema que son comúns ó resto de Europa, albiscándose unha postura tradicional e outra partidaria das novas ideas da antropoloxía e da arqueoloxía prehistórica.

Estas son, de xeito moi resumido, as características do panorama arqueolóxico da Galicia decimonónica. Qué papel xogou Leandro Saralegui y Medina en todo isto é o que queda agora por determinar.

En primeiro lugar, Saralegui, a pesar de recoñecer constantemente a importancia dos estudios arqueolóxicos para coñece-lo pasado galego 
máis remoto, e malia as súas contínuas chamadas a realizalos, non contribuiu á práctica arqueolóxica; non levou a cabo escavacións nin estudiou material arqueolóxico galego. Sen embargo artigos publicados os derradeiros anos da súa vida («Adobrica» ou «Libunca») amosan a Saralegui «explorando»(?) os castros da zona de Ferrol (probablemente realizando prospeccións superficiais).

En segundo lugar, aínda que Saralegui utilizou nas súas obras sobre o pasado pre-romano de Galicia información tirada dos restos arqueolóxicos en maior medida que outros autores contemporáneos (exceptuando, por suposto, a aqueles que realizaron verdadeiros traballos arqueolóxicos como Villaamil y Castro ou Maciñeira), tamén é verdade que o emprego desta era bastante superficial, limitándose a facer referencia a restos arqueolóxicos (castros, megalitos, machados de pedra, obxectos de metal, etc.) e a presentalos como proba das súas opinións, condicionadas estas polo seu «Celtismo»e por algunhas teorías arqueolóxicas e antropolóxicas en voga no momento (e, por suposto, pola súa ideoloxía).

Deste xeito, pódese dicir que a antiga historia de Galicia esbozada por Saralegui estaba aínda baseada fundamentalmente nos textos clásicos (por exemplo as probas que daba da presencia celta, fenicia, grega ou cartaxinesa; as características da sociedade celta...). Sen embargo tamén é importante salientar que unha vez recoñecida unha longa etapa prehistórica moi anterior ós celtas Saralegui non tiña máis remedio que apoiarse unicamente na información arqueolóxica para poder coñecer algo sobre ela. E iso foi precisamente o que fixo, deseñando un esquema da prehistoria galega, en grande parte pioneiro, con base na información arqueolóxica, aínda que esta, como xa dixen, era inserida máis ou menos acriticamente nun aparello teórico previo, neste caso o fornecido polos esquemas da prehistoria europea construídos ó longo da segunda metade do século (Paleolítico, Neolítico, pobo dos túmulos, invasións indoeuropeas...). Así, con Villaamil y Castro e con Saralegui, a prehistoria galega faise prehistoria europea.

Pero Saralegui tamén seguía dentro da «ortodoxia» do «Celtismo», co que se mantiña fiel ós postulados da historiografía galeguista do século XIX. Con todo, hai que salientar que o «Celtismo» non lle impedía a Saralegui interesarse por outros periodos da prehistoria anteriores ós celtas. Así, el foi un dos autores galegos da época que máis se interesou 
polas cuestións da humanidade primitiva, acerca da cal mantivo opinións que se afastaban da visión tradicional, a admitida pola Igrexa, aceptando por exemplo a grande antigüidade da humanidade e a súa situación de «salvaxismo» inicial; non aceptou, sen embargo a opinión, máis radical daquela, da orixe simia dos seres humanos. E tampouco quixo polemizar cos sectores máis conservadores que seguían rexeitando as teorías da arqueoloxía prehistórica e da antropoloxía evolucionista, aínda que tampouco quixo agachar aquelas ideas que podían semellar pouco «ortodoxas» para o conservador clero galego (no cal, a pesar de que rexeitaba ideas como o da grande antigüidade ou a do «salvaxismo» orixinal da humanidade non se achan críticas a Saralegui por telas defendido en Galicia).

Quero salientar, por último, a familiaridade de Saralegui con moitas das teorías arqueolóxicas, antropolóxicas, históricas ou lingüísticas que estaban presentes en Europa por aquel entón. Son frecuentes na obra deste autor referencias ás ideas de investigadores como John Lubbock, Gabriel de Mortillet, Emille Cartailhac, Armand de Quatrefages, Edward B. Tylor, Herbert Spencer, Agustin Thierry, Jules Michelet, Max Müller ou Ernest Renan, entre outros, e as súas influencias son discernibles nas ideas de Saralegui. As opinións antropolóxicas e arqueolóxicas deste autor incluíanse, pois, na meirande parte das veces nas correntes de pensamento europeo.

Leandro de Saralegui y Medina non foi un arqueólogo, nin un prehistoriador, nin un antropólogo. Foi un home interesado por todos estes temas (e por moitos máis) que sen embargo viviu nun país e nunha época - a Galicia do século XIX e primeira década do XX - no que tanto a arqueoloxía, e en especial a arqueoloxía prehistórica, e a antropoloxía, estaban escasamente desenvolvidas (e no caso da antropoloxía, física ou cultural, esta era practicamente inexistente, agás algúns estudios de folklore); incluso a arqueoloxía prehistórica era mal vista polos sectores relixiosos e conservadores, daquela dominantes. Con todo, Saralegui quixo da-la súa versión da historia máis antiga de Galicia, apoiado na información arqueolóxica e seguindo as teorías vixentes no momento. Por isto e polo seu interese en que os estudios arqueolóxicos se divulgasen entre a poboación galega, interese plasmado nas tres edicións dos seus Estudios sobre la época céltica en Galicia e nos seus artigos de tema arqueolóxico, merece ser lembrado na historia da arqueoloxía galega a carón de Villaamil y Castro, Murguía, Marcelo Macías ou Maciñeira. 


\section{BIBLIOGRAFÍA}

BARREIRO FERNÁNDEZ, X. R. (1988): «A Historia da Historia. Aproximación a unha historiografía galega (séculos XVI a XIX)» en X. Castro e J. de Juana (eds.) IV Xornadas de Historia de Galicia. Historiografía Galega, p. 17-78. Ourense.

Deputación Provincial.

- (1993): «A Historia da Historia. Aproximación a unha historiografía galega: De Murguía a Risco» en J. G. Beramendi (coord.) Galicia e a historiografía, p. 183-209. Colección Sémata. Santiago. Tórculo Edicións.

BOWLER, P. J. (1989): The Invention of Progress. The Victorians and the Past. Oxford. Basil Blackwell.

FRAGA VÁZQUEZ, X. A. (1992): Bioloxía na Galiza na segunda metade do século XIX (1968-1903): ensino, divulgación, debates, producción, institucionalización e recepción de novidades. Tese de Doutoramento inédita. Santiago. Universidade de Santiago de Compostela.

- (1993): «Recepción do Darwinismo na Galiza. Primeiras reaccións (1859-1874)» en Historia Nova I. Contribución dos Xóvenes Historiadores de Galicia; p. 205-215. Santiago. Asociación Galega de Historiadores.

LLANA RODRÍGUEZ, C. (1990): El Problema de la Ordenación del Espacio en el Paleolítico Superior de Galicia y Asturias: El territorio económico. Tese de Doutoramento inédita. Santiago. Universidade de Santiago de Compostela.

- (1994): «José Villaamil y Castro. La Investigación Paleolitista en la Galicia del siglo XIX» en Revista de Arqueología, $\mathrm{n}^{\circ}$ 163; $\mathrm{p}$. 52-59.

MAIZ, R. (1984): O Rexionalismo Galego: Organización e Ideoloxía (1886-1907). Sada. Ediciós do Castro.

"CUADERNOS DE ESTUDIOS GALLEGOS", Tomo XLIII, Fascículo 108, Santiago 1996. 
MATO DOMÍNGUEZ, J. A. (1981): Historiografía y Nacionalismo. La Construcción histórica de Galicia por los historiadores gallegos del siglo XIX y primer tercio del XX. Tese de Licenciatura inédita. Santiago. Universidade de Santiago de Compostela.

MAYOBRE RODRIGUEZ, P. (1985): Debates ideolóxicos na Compostela do XIX. Sada. Ediciós do Castro.

PEREIRA GONZÁLEZ, F. (1995): O emprego da información arqueolóxica en Galicia: 1800-1922. Traballo de Investigación do Terceiro Ciclo inédito. Santiago. Universidade de Santiago de Compostela.

- (1996a): Contribución á historia da arqueoloxía en Galicia: As opinións sobre a humanidade primitiva e a información arqueolóxica na Galicia do século XIX. Tese de Licenciatura inédita. Santiago. Santiago de Compostela.

- (1996b): «Unha contribución ó estudio da arqueoloxía galega: o emprego da información arqueolóxica en Galicia (1800-1922)» en Gallaecia. Publicación do Departamento de Historia I da Facultade de Xeografía e Historia da Universidade de Santiago, n 14-15; p. 7-29.

POLIAKOV, L. (1971): Le Mythe Aryen. París. Calmann-Lévy.

SARALEGUI Y MEDINA, L. (1867): Estudios sobre la época céltica en Galicia. $1^{\text {a }}$ edición. Ferrol.

- (1870): Tratado de Economía Política. $1^{\text {a }}$ edición. Ferrol.

- (1888): Estudios sobre Galicia. A Coruña.

- (1893): «La cuestión obrera en Galicia» en Galicia (Revista Regional de Ciencias, Letras, Arte, Folklore...), $\mathrm{n}^{\circ} 8$.

- (1894): Estudios sobre la época céltica en Galicia. $3^{\mathrm{a}}$ edición. Ferrol. - (1908): «Adobrica. Estudio de Geografía Histórica» en Almanaque de Ferrol para 1909; p. 135-145.

- (1909): «Libunca. Estudio histórico» en Almanaque de Ferrol para 1910; p. 156-168.

VIEITES TORREIRO, D. (1987): El Celtismo en la Historiografía Gallega. Tese de Licenciatura inédita. Santiago. Universidade de Santiago de Compostela.

"CUADERNOS DE ESTUDIOS GALLEGOS", Tomo XLIII, Fascículo 108, Santiago 1996. 